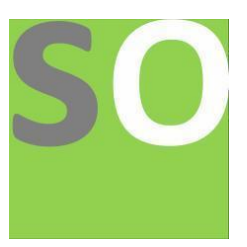

Article title: Design \& Control of a Gantry Crane System with Limited Payload Angle using Robust \& State Feedback Controllers

Authors: Mustefa Jibril[1], Messay Tadese[2], Reta Degefa[3]

Affiliations: School of Electrical and Computer Engineering[1]

Orcid ids: 0000-0002-3165-2410[1]

Contact e-mail: mustefazinet1981@gmail.com

License information: This work has been published open access under Creative Commons Attribution License http://creativecommons.org/licenses/by/4.0/, which permits unrestricted use, distribution, and reproduction in any medium, provided the original work is properly cited. Conditions, terms of use and publishing policy can be found at https://www.scienceopen.com/.

Preprint statement: This article is a preprint and has not been peer-reviewed, under consideration and submitted to ScienceOpen Preprints for open peer review.

DOI: 10.14293/S2199-1006.1.SOR-.PPB0TPJ.v1

Preprint first posted online: 17 August 2020

Keywords: Gantry crane, Trolley, Payload, H 2 optimal, Observer based controller 


\title{
Design \& Control of a Gantry Crane System with Limited Payload Angle using Robust \& State Feedback Controllers
}

\author{
Mustefa Jibril ${ }^{1}$, Messay Tadese ${ }^{2}$, Reta Degefa ${ }^{3}$ \\ ${ }^{1}$ Msc, School of Electrical \& Computer Engineering, Dire Dawa Institute of Technology, Dire Dawa, \\ Ethiopia \\ ${ }^{2}$ Msc, School of Electrical \& Computer Engineering, Dire Dawa Institute of Technology, Dire Dawa, \\ Ethiopia \\ ${ }^{3}$ Msc, School of Electrical \& Computer Engineering, Dire Dawa Institute of Technology, Dire Dawa, \\ Ethiopia \\ mustefa.jibril@ddu.edu.et
}

\begin{abstract}
In this paper, the performance improvement of a payload angle deflection of a gantry crane has been studied and simulated using Matlab/Simulink toolbox successfully. H 2 optimal and observer based controllers has been used to minimize the payload angular deflection by controlling the trolley position. The gantry crane has been compared with the proposed controllers to track the reference trolley position using step and sine wave signals and a promising results have been achieved.
\end{abstract}

Keywords: Gantry crane, Trolley, Payload, H 2 optimal, Observer based controller

\section{Introduction}

A gantry crane is one of the many types of crane which is built at the top of a gantry, which is a structure used to support an object to be lifted. They are huge machines that capable of lifting heavy loads like lifting automobile engines out of vehicles. The terms gantry crane and overhead crane (or bridge crane) are often used interchangeably, as both types of crane straddle their workload. The distinction mass often drawn between the two is that with gantry cranes, the entire composition (including gantry) is usually wheeled (often on rails). By contrast, the promoting makeups of an overhead crane is fixed in location, often in the example of the walls or ceiling of a building, to which is attached a movable hoist running overhead along a bannister or ray (which may itself move). Further confusing the issue is that gantry cranes may also incorporate a movable beam-mounted hoist in addition to the entire structure entity wheeled, and some overhead cranes are suspended from a freestanding gantry. Full gantry cranes (where the load remnants beneath the gantry structure, supported from a beam) are well suited to lifting massive thing such as ships' engines, as the entire disposition can resist the torque created by the load, and counterweights are generally not required. These are often found in shipyards where they are used to move large boat part together for construction.

\section{Mathematical Modeling of Gantry Crane}

The gantry crane system design is shown in Figure 1 below. 


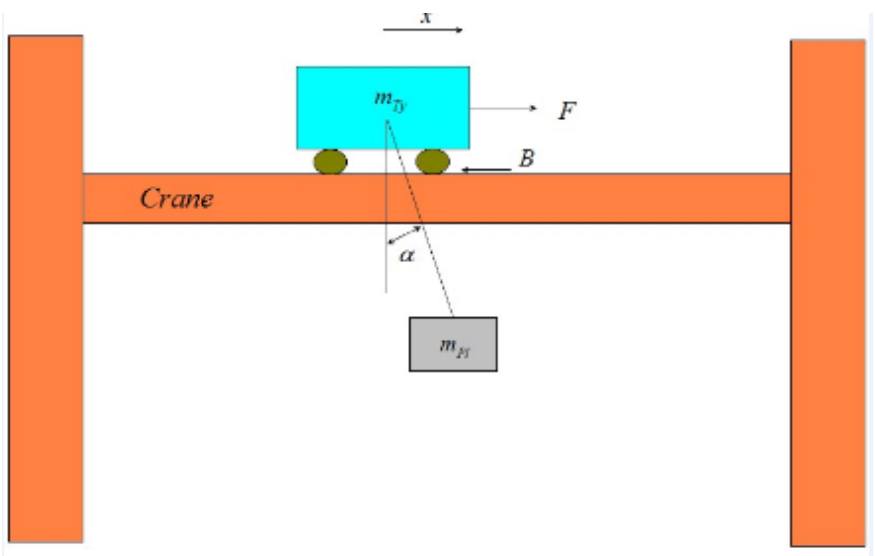

Figure 1 Gantry crane system

To solve the mathematical model of the system, Lagrange's equations are used which is given as

$$
\begin{gathered}
\frac{d}{d t}\left(\frac{\partial L}{\partial \dot{\theta}}-\frac{\partial L}{\partial \theta}\right)=Q \\
L=T-V \quad(2)
\end{gathered}
$$

Where

$\theta$ System variable

$L$ Lagrange equation

$Q$ Sum of forces or moments

$T$ Kinetic energies

$V$ Potential energies

The kinetic energy of the trolley given as:

$$
T_{1}=\frac{1}{2} m_{T y} \dot{x}^{2}
$$

The kinetic energy of the payload is given as

$$
T_{2}=\frac{1}{2} m_{P l} v^{2}
$$

And the velocity is found by taking the first derivative of the position:

$$
\begin{aligned}
& v^{2}=\dot{x}^{2}+2 l \dot{\alpha} \dot{x} \sin \alpha+l^{2} \dot{\alpha}^{2} \\
& T_{2}=\frac{1}{2} m_{P l}\left(\dot{x}^{2}+2 l \dot{\alpha} \dot{x} \sin \alpha+l^{2} \dot{\alpha}^{2}\right)
\end{aligned}
$$


The Lagrangian for this system can be written as:

$$
L=\frac{1}{2} m_{P l}\left(\dot{x}^{2}+2 l \dot{\alpha} \dot{x} \sin \alpha+l^{2} \dot{\alpha}^{2}\right)+\frac{1}{2} m_{T y} \dot{x}^{2}+m_{P l} g l \cos \alpha
$$

And the equation of motion follows from:

$$
\frac{d}{d t}\left(\frac{\partial L}{\partial \dot{x}}-\frac{\partial L}{\partial x}\right)=F-B \dot{x}
$$

Where $\mathrm{B}$ is the damping friction coefficient

$$
\frac{d}{d t}\left(\frac{\partial L}{\partial \dot{\alpha}}-\frac{\partial L}{\partial \alpha}\right)=0
$$

Resulting in:

$$
\begin{gathered}
\left(m_{T y}+m_{P l}\right) \ddot{x}+B \dot{x}+m_{P l} l \ddot{\alpha} \cos \alpha-m_{P l} l \dot{\alpha}^{2} \sin \alpha=F \\
m_{P l} l^{2} \ddot{\alpha}+m_{P l} l \ddot{x} \cos \alpha+m_{P l} l g \sin \alpha=0
\end{gathered}
$$

For small angle approximation: $\alpha<1^{0}$ the sine and cosine can be linearized as

$$
\begin{aligned}
& \alpha \approx 0 \\
& \sin \alpha \approx \alpha \\
& \cos \alpha \approx 1 \\
& \dot{\alpha}^{2} \approx 0
\end{aligned}
$$

Hence, the derived Equation (7) and (8) of the non-linear model can be approximately linearized as:

$$
\begin{gathered}
\left(m_{T y}+m_{P l}\right) \ddot{x}+B \dot{x}+m_{P l} l \ddot{\alpha}=F \\
m_{P l} l^{2} \ddot{\alpha}+m_{P l} l \ddot{x}+m_{P l} \lg \alpha=0
\end{gathered}
$$

Rearranging Equation (9) and (10)

$$
\begin{gathered}
\ddot{x}=-\frac{B}{m_{P l}} \dot{x}+\frac{m_{T y} g}{m_{P l}} \alpha+\frac{F}{m_{P l}} \\
\ddot{\alpha}=\frac{B}{m_{P l} l} \dot{x}-\frac{\left(m_{P l}+m_{T y}\right)}{m_{P l} l} g \alpha+-\frac{F}{m_{P l} l}
\end{gathered}
$$

Let

$$
x_{1}=x, x_{2}=\dot{x}, x_{3}=\alpha \text { and } x_{4}=\dot{\alpha}
$$


The state space equation becomes

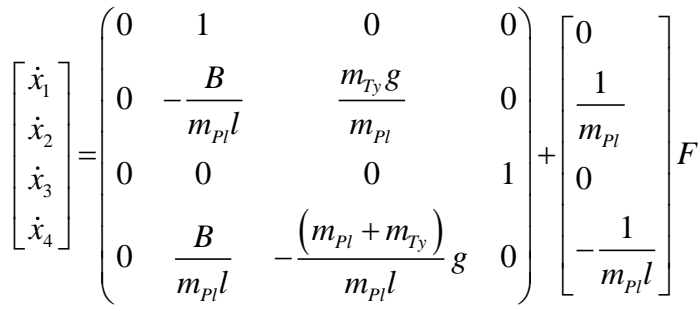

$$
\begin{aligned}
& y=\left[\begin{array}{llll}
1 & 0 & 0 & 0 \\
0 & 0 & 1 & 0
\end{array}\right]\left[\begin{array}{l}
\dot{x}_{1} \\
\dot{x}_{2} \\
\dot{x}_{3} \\
\dot{x}_{4}
\end{array}\right]
\end{aligned}
$$

The system parameters are shown in Table 1 below.

Table 1 System parameters

\begin{tabular}{|l|l|l|l|}
\hline No & Parameters & Symbols & Values \\
\hline 1 & Trolley mass & $m_{T y}$ & $80 \mathrm{Kg}$ \\
\hline 2 & Payload mass & $m_{P l}$ & $32 \mathrm{Kg}$ \\
\hline 3 & Surface friction & $B$ & $25 \mathrm{~N}-\mathrm{m} / \mathrm{s}$ \\
\hline & Cable length & $l$ & $3.5 \mathrm{~m}$ \\
\hline & Acceleration due to gravity & $g$ & $10 \mathrm{~m} / \mathrm{s}^{\wedge} 2$ \\
\hline
\end{tabular}

Then the state space equation numerically becomes

$$
\begin{aligned}
& {\left[\begin{array}{l}
\dot{x}_{1} \\
\dot{x}_{2} \\
\dot{x}_{3} \\
\dot{x}_{4}
\end{array}\right]=\left[\begin{array}{cccc}
0 & 1 & 0 & 0 \\
0 & -0.22 & 25 & 0 \\
0 & 0 & 0 & 1 \\
0 & 0.22 & -10 & 0
\end{array}\right)+\left[\begin{array}{l}
0 \\
0.03 \\
0 \\
-0.009
\end{array}\right] F} \\
& y=\left[\begin{array}{llll}
1 & 0 & 0 & 0 \\
0 & 0 & 1 & 0
\end{array}\right]\left[\begin{array}{l}
\dot{x}_{1} \\
\dot{x}_{2} \\
\dot{x}_{3} \\
\dot{x}_{4}
\end{array}\right]
\end{aligned}
$$

\section{The Proposed Controllers Design}

\subsection{Observer-Based Controller Design}

The deal with the general argument where only a subset of the states, or linear combinations of them, are obtained from measurements and are available to our controller. Such a handbooks lines is referred to as the output feedback problem.

The output is of the form

$$
y=C x+D u
$$


The block diagram of the gantry crane system with the observer-based controller is shown in Figure 2 bellow.

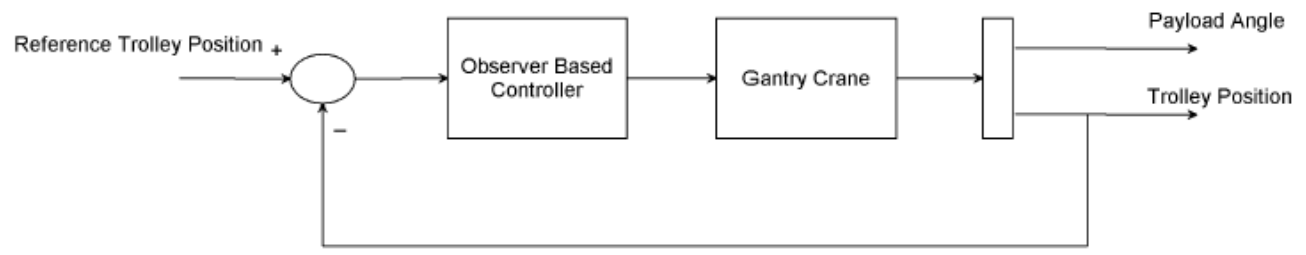

Figure 2 Block diagram of the gantry crane system with the observer-based controller The observer based controller Gc(s) can be further derived in the following form:

$$
G_{c}(s)=I-K(s I-A+B K+H C)^{-1} B
$$

With its state space realization

$$
G_{c}(s)=\left[\begin{array}{cc}
A-B K-H C & B \\
-K & I
\end{array}\right]
$$

The controller Gc(s) in Equation (15) is called the observer-based controller, since the structural reference of the observer is reflected within the controller.

Where the state space model of the plant, $\mathrm{G}$, the state feedback gain vector $\mathrm{K}$, and the observer gain vector $\mathrm{H}$ are then returned, respectively.

We select the weighting matrix $\mathrm{Q}$ and $\mathrm{R}$ as

$$
Q=\left(\begin{array}{llll}
3 & 0 & 0 & 0 \\
0 & 3 & 0 & 0 \\
0 & 0 & 3 & 0 \\
0 & 0 & 0 & 3
\end{array}\right) \text { and } R=5
$$

And we select the observer gain vector as

$$
H=\left(\begin{array}{cc}
1.5 & -0.3 \\
0.4 & 1.2 \\
0.7 & 0 \\
0.9 & -0.5
\end{array}\right)
$$

And we obtain the state feedback gain vector $\mathrm{K}$ as

$$
K=\left[\begin{array}{llll}
0.7746 & 86.0062 & 70.8594 & 212.6783
\end{array}\right]
$$

The observer-based controller state space representation become 


$$
\begin{aligned}
& \dot{x}_{o}=\left(\begin{array}{cccc}
-1.5 & 1 & 0 & 0 \\
-0.42 & -2.8 & 22.87 & -6.38 \\
-0.7 & 0 & 0 & 1 \\
-0.9 & 1 & -9.362 & 1.9
\end{array}\right) x+\left(\begin{array}{l}
1.5 \\
0.4 \\
0.7 \\
0.9
\end{array}\right) u_{o} \\
& y_{o}=\left(\begin{array}{llll}
0.77 & 86 & 71 & 212.7
\end{array}\right) x_{o}
\end{aligned}
$$

\subsection{Augmentations of the Model with Weighting Functions}

In this section, we will center on the weighted control system shown in Figure 3, where W1(s), $\mathrm{W} 2(\mathrm{~s})$, and $\mathrm{W} 3$ (s) are weighting functions or weighting filters. We assume that $\mathrm{G}(\mathrm{s})$ (gantry crane system), W1(s), and W3(s) G(s) are all proper; i.e., they are bounded when $s \rightarrow \infty$. It can be seen that the weighting function W3(s) is not required to be proper. In the two-port system, the output vector $\mathrm{y} 1=[\mathrm{y} 1 \mathrm{a}, \mathrm{y} 1 \mathrm{~b}, \mathrm{y} 1 \mathrm{c}] \mathrm{T}$ is not used directly to construct the vector $\mathrm{u} 2$. Understand that $\mathrm{y} 1$ is actually for the control outline attainment measurement. So, it is not strange to include the filtered "input signal" $u(t)$ in the "output signal" y1 because one may indispensability to quantities the control energy to assess whether the designed controller is perfect or not. Clearly, Figure 2 represents a more general diagram of optimal and robust control systems. We can design an optimal $\mathrm{H} 2$ controller by using the thought of the augmented system model.

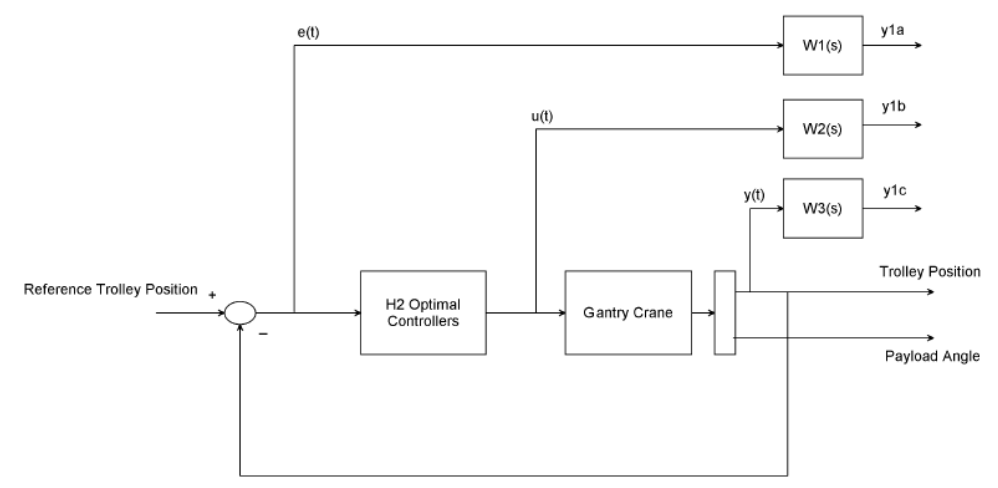

Figure 3 weighted control structure of the gantry crane system with the $\mathrm{H} 2$ optimal controller The weighting function $\boldsymbol{W} 1(s), \boldsymbol{W} 2(s)$, and $\boldsymbol{W} 3(s)$ are chosen as

$$
W_{1}(s)=\frac{s+1}{s^{2}+6 s+12} \quad W_{2}(s)=\frac{s+4}{s^{2}+16 s+42} \quad W_{3}(s)=\frac{s+8}{s^{2}+21 s+55}
$$

The H 2 optimal controller state space representation become 


$$
\begin{aligned}
& {\left[\begin{array}{l}
\dot{z}_{1} \\
\dot{z}_{2} \\
\dot{z}_{3} \\
\dot{z}_{4}
\end{array}\right]=\left(\begin{array}{cccc}
0.43 & 1.27 & 2.05 & 23 \\
20 & 32 & 45 & 10 \\
0.9 & -0.35 & 12 & 1 \\
34 & 22 & -0.45 & 0
\end{array}\right)+\left[\begin{array}{l}
20 \\
13 \\
0.54 \\
-5
\end{array}\right] u} \\
& w=\left[\begin{array}{lll}
27.98 & 0 & 0.936
\end{array}\right]\left[\begin{array}{l}
\dot{z}_{1} \\
\dot{z}_{2} \\
\dot{z}_{3} \\
\dot{z}_{4}
\end{array}\right]
\end{aligned}
$$

\section{Result and Discussion}

\subsection{Comparison of the Gantry Crane System using Augmentation Based H 2 Optimal \&}

Observer Based Controllers for a Step Input Trolley Position Signal

The Simulink model of the gantry crane system using augmentation based H 2 optimal \& observer based controllers using step input desired trolley position signal is shown in Figure 4 below.

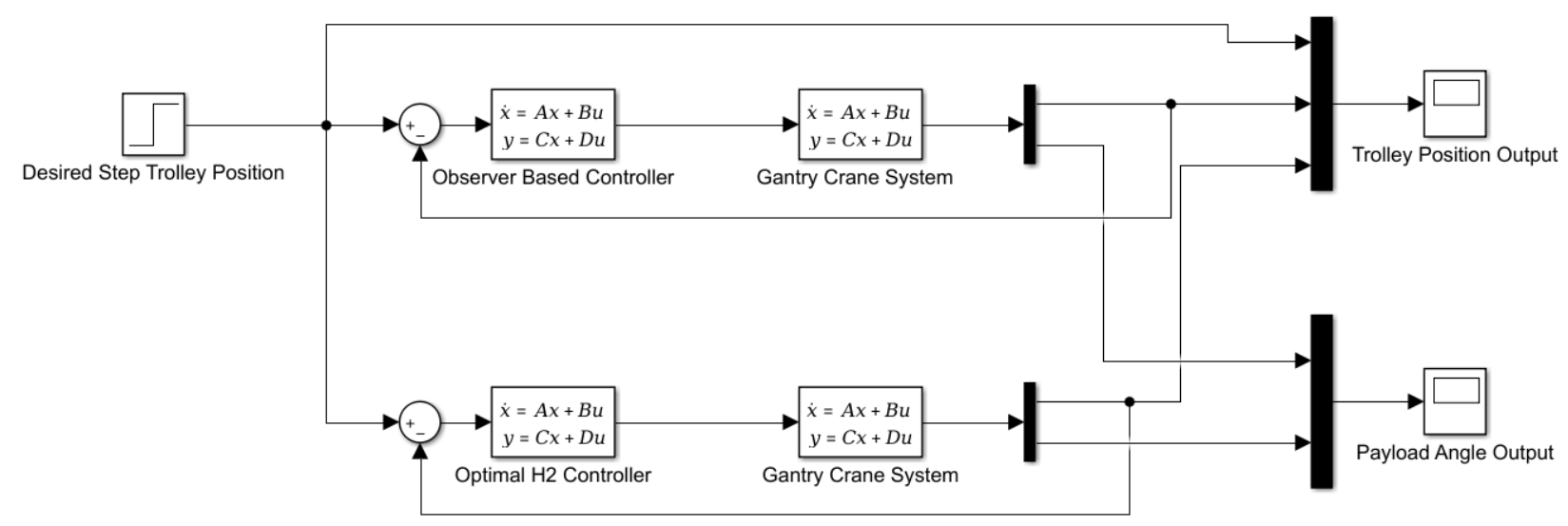

Figure 4 Simulink model of the gantry crane system using augmentation based H 2 optimal \& observer based controllers using step input desired trolley position signal

The simulation result of the trolley and payload comparison for the proposed controllers and the input force to the gantry crane system are shown in Figure 5, Figure 6, Figure 7 and Figure 8 respectively. 


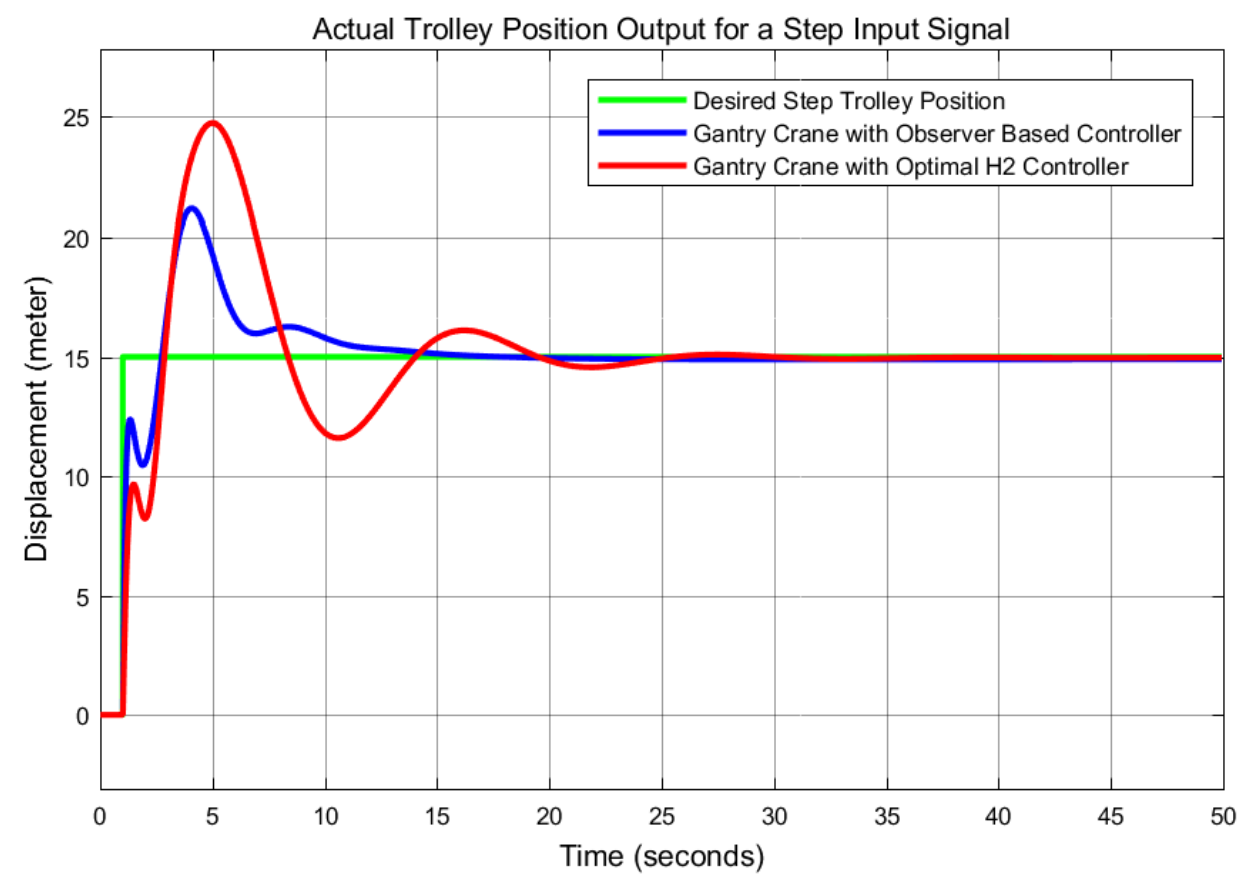

Figure 5 Step response of the trolley position comparison

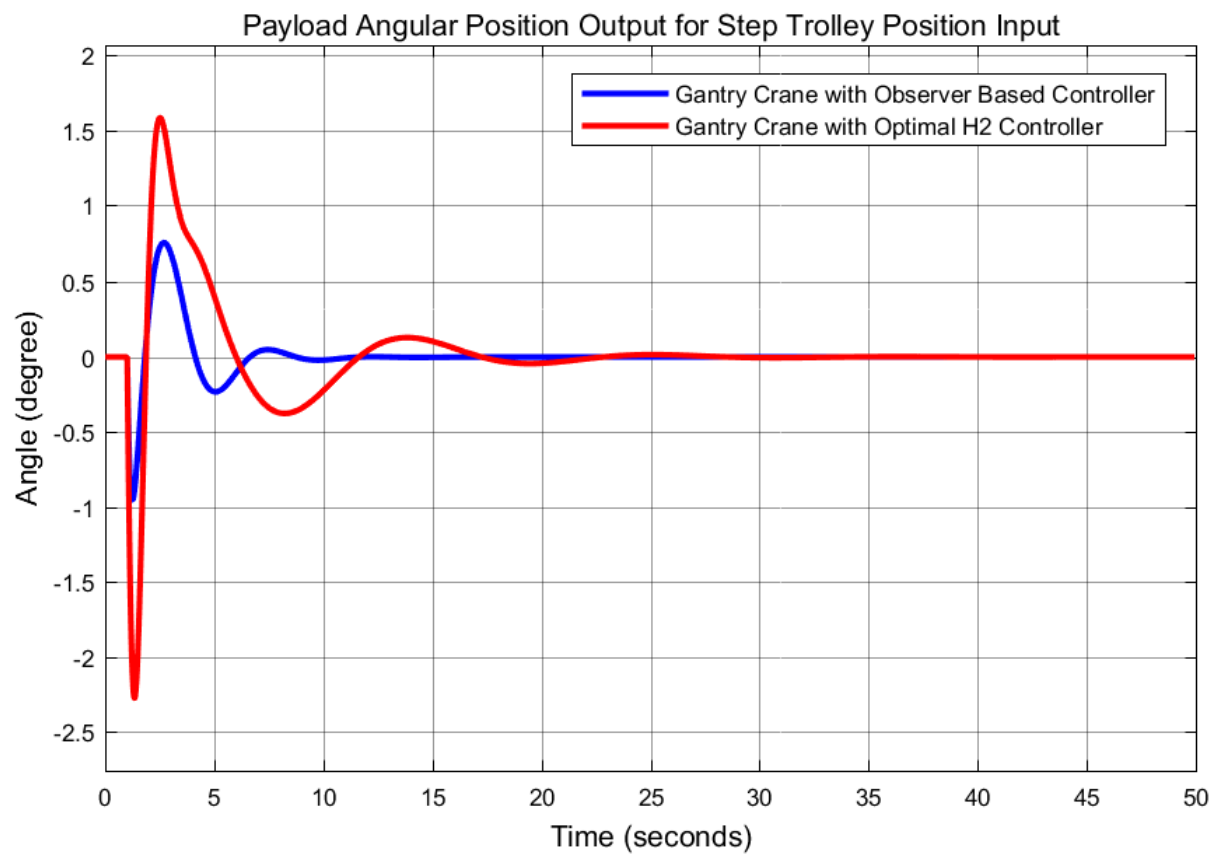

Figure 6 Step response of the trolley position comparison 


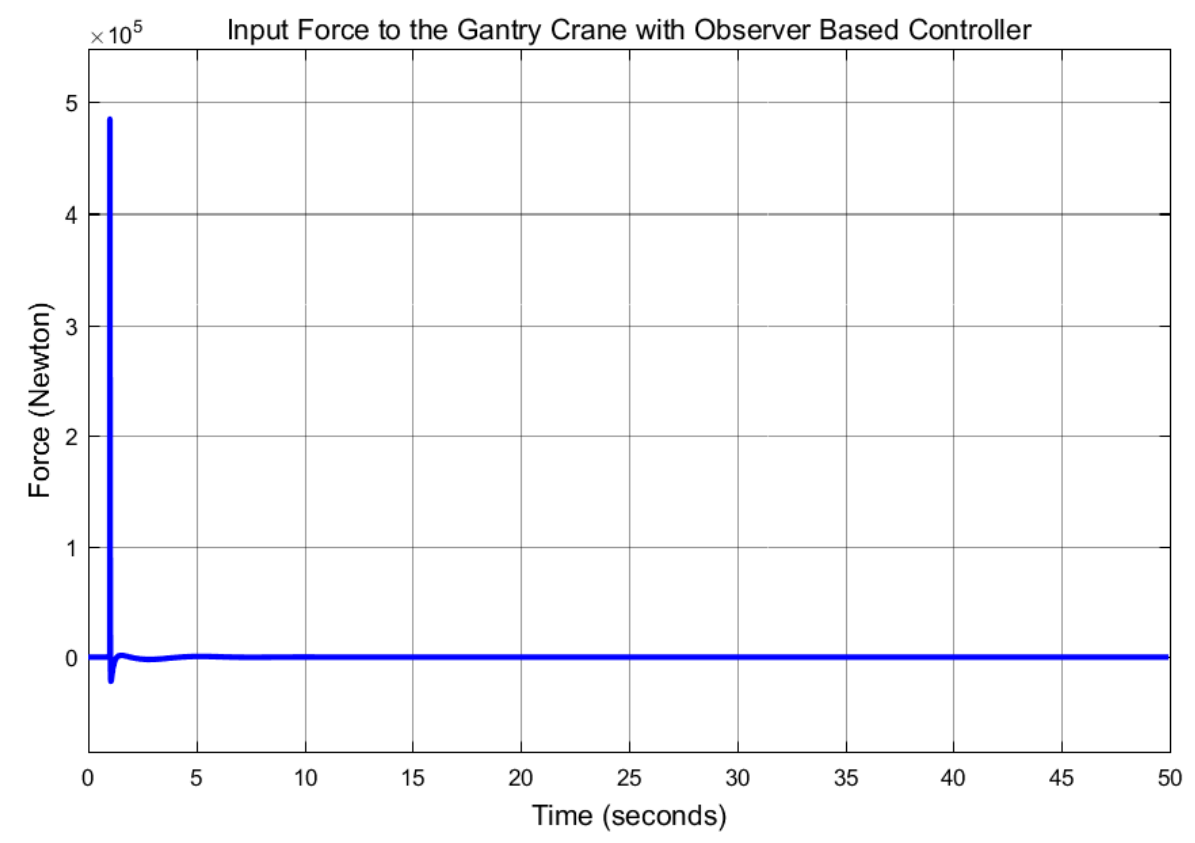

Figure 7 Input Force to the system with observer based controller

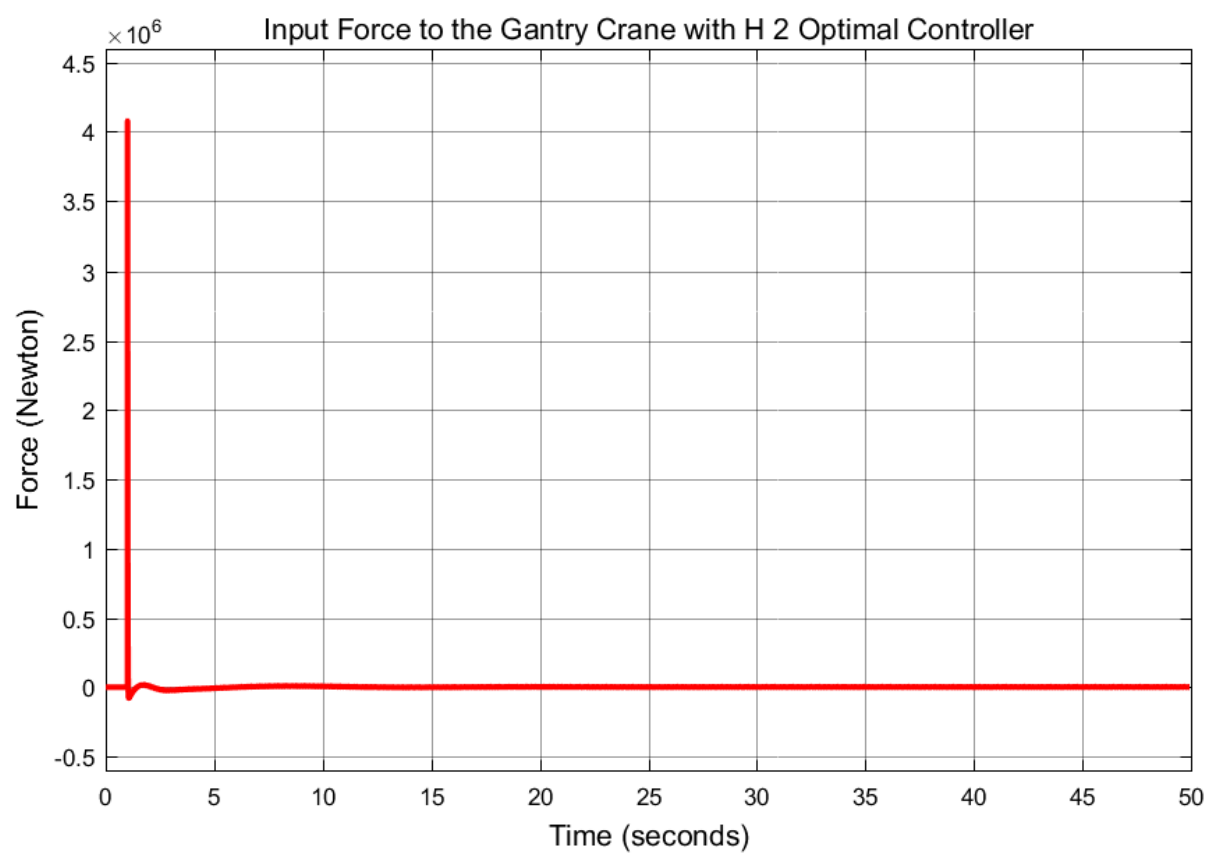

Figure 8 Input Force to the system with H 2 optimal controller

The input force of the gantry crane system with the observer based controller shows improvement in reducing the force amplitude. The data of the rise time, percentage overshoot and settling time of the trolley is shown in Table 2.

Table 2 Trolley step response data

\begin{tabular}{|l|l|l|l|}
\hline No & Performance Data & Observer based controller & H 2 optimal controller \\
\hline
\end{tabular}




\begin{tabular}{|l|l|l|l|}
\hline 1 & Rise time & $1 \mathrm{sec}$ & $1.1 \mathrm{sec}$ \\
\hline 2 & Per. overshoot & $26.6 \%$ & $46.6 \%$ \\
\hline 3 & Settling time & $15 \mathrm{sec}$ & $30 \mathrm{sec}$ \\
\hline
\end{tabular}

As Table 2 shows that the gantry crane system with the observer based controller improves the performance of the Trolley position by minimizing the percentage overshoot and settling time.

The data of the rise time, percentage overshoot and settling time of the payload is shown in Table 3.

Table 3 Payload step response data

\begin{tabular}{|l|l|l|l|}
\hline No & Performance Data & \multicolumn{1}{|c|}{ Observer based controller } & H 2 optimal controller \\
\hline 1 & Rise time & $1 \mathrm{sec}$ & $1 \mathrm{sec}$ \\
\hline 2 & Per. overshoot & $18.6 \%$ & $35.6 \%$ \\
\hline 3 & Settling time & $10 \mathrm{sec}$ & $28 \mathrm{sec}$ \\
\hline
\end{tabular}

As Table 3 shows that the gantry crane system with the observer based controller improves the performance of the payload angle by minimizing the percentage overshoot and settling time.

\subsection{Comparison of the Gantry Crane System using Augmentation Based H 2 Optimal \& Observer Based Controllers for a Sine Wave Input Trolley Position Signal}

The Simulink model of the gantry crane system using augmentation based H 2 optimal \& observer based controllers using sine wave input desired trolley position signal is shown in Figure 9 below.

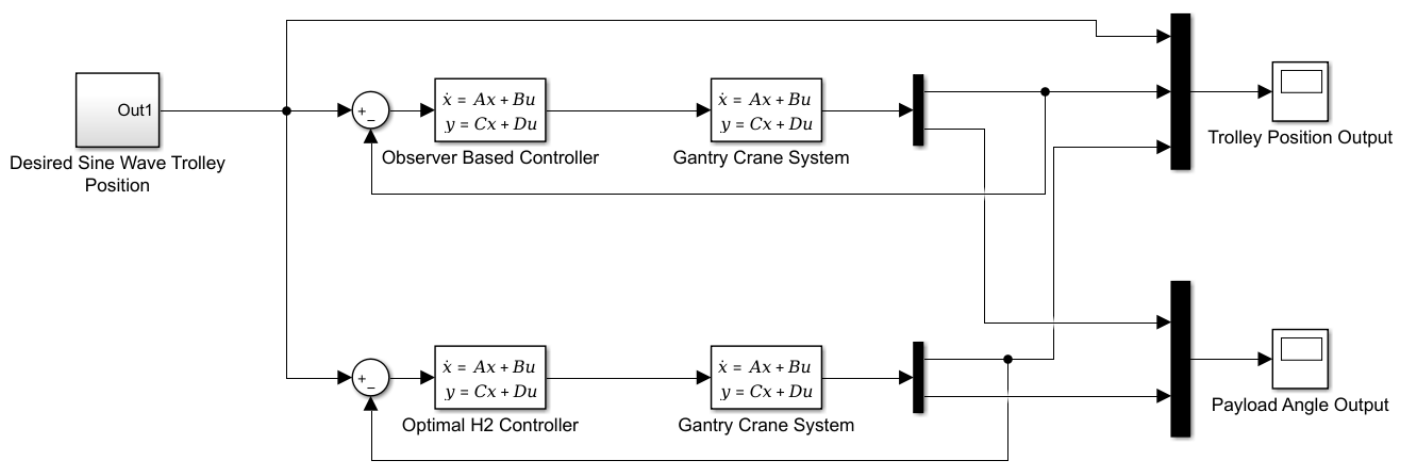

Figure 9 Simulink model of the gantry crane system using augmentation based $\mathrm{H} 2$ optimal \& observer based controllers using sine wave input desired trolley position signal

The simulation result of the trolley and payload comparison for the proposed controllers and the input force to the gantry crane system are shown in Figure 10, Figure 11, Figure 12 and Figure 13 respectively. 


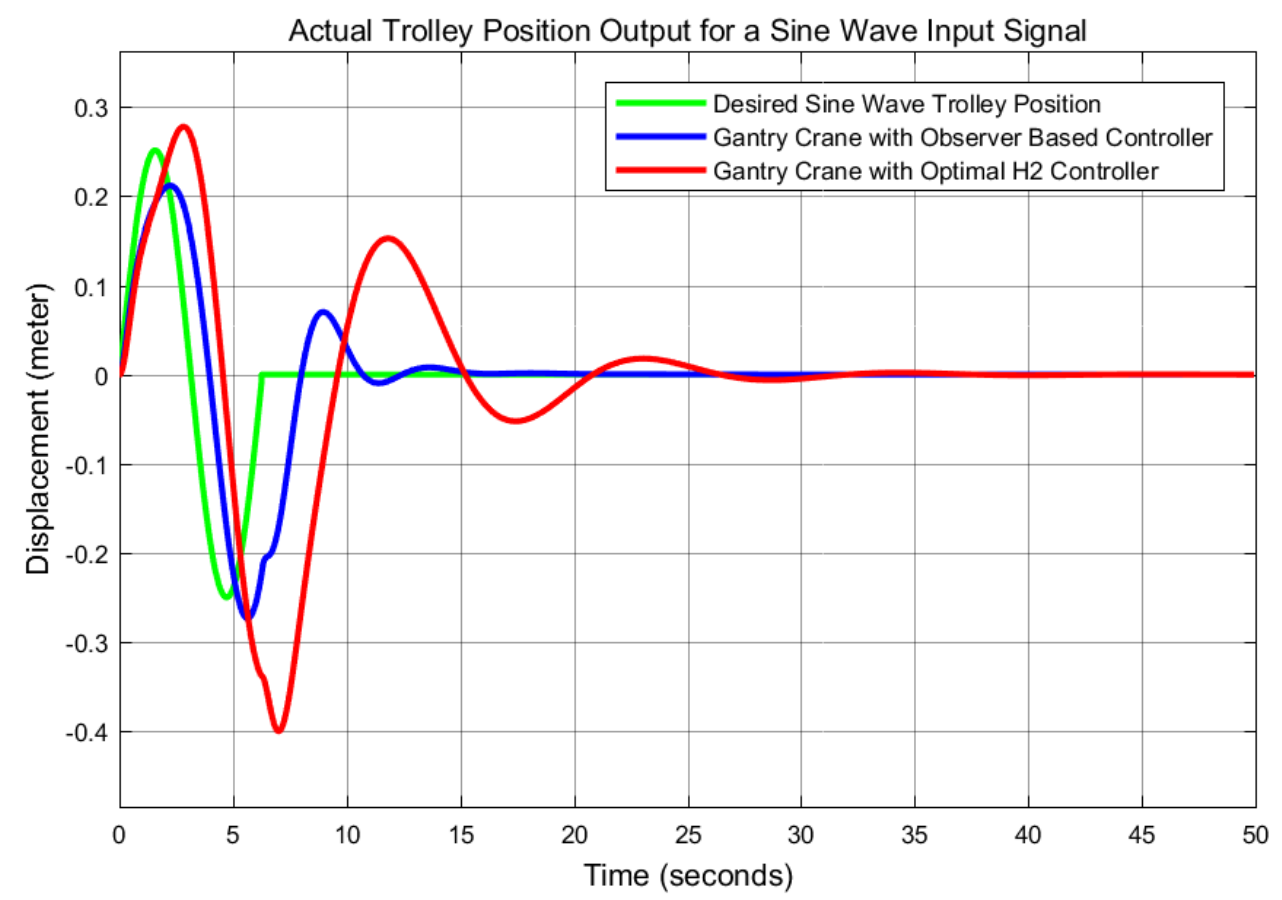

Figure 10 Sine wave response of the trolley position comparison

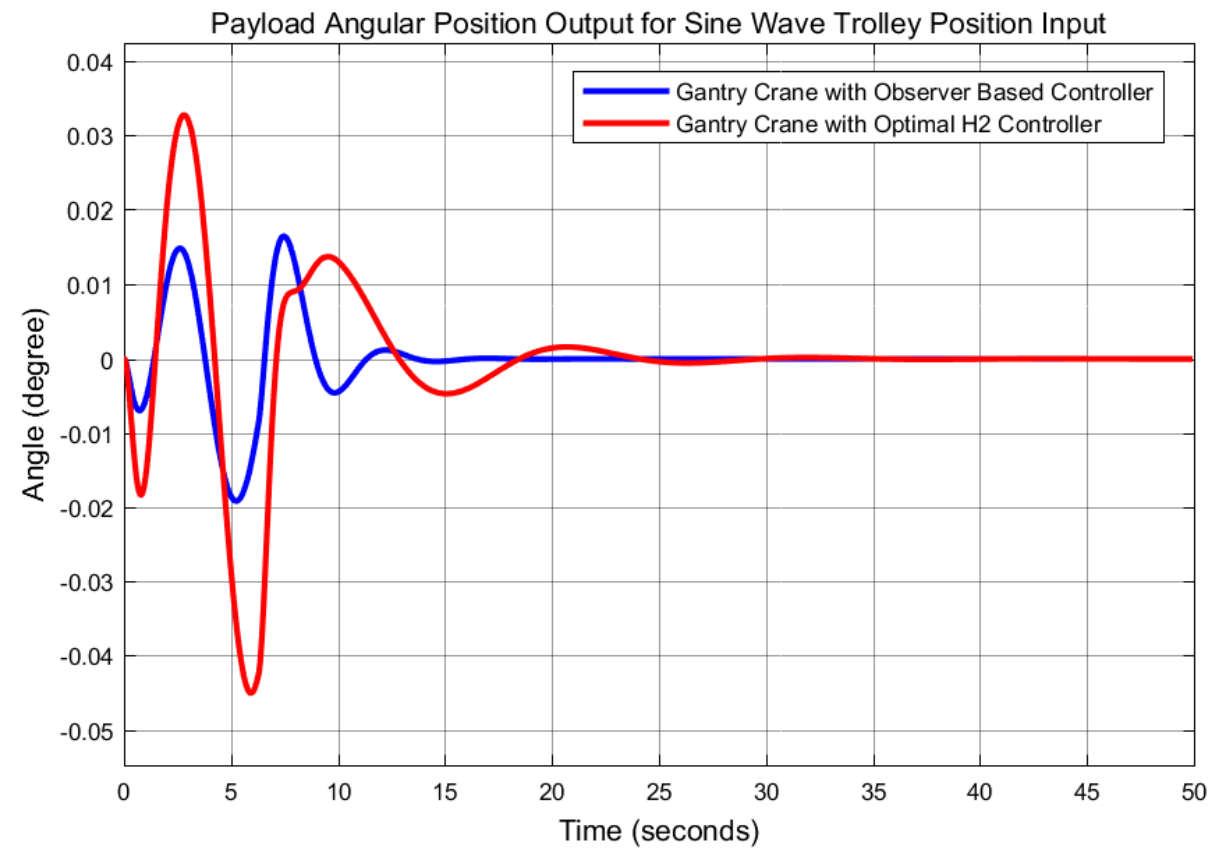

Figure 11 Sine wave response of the trolley position comparison 


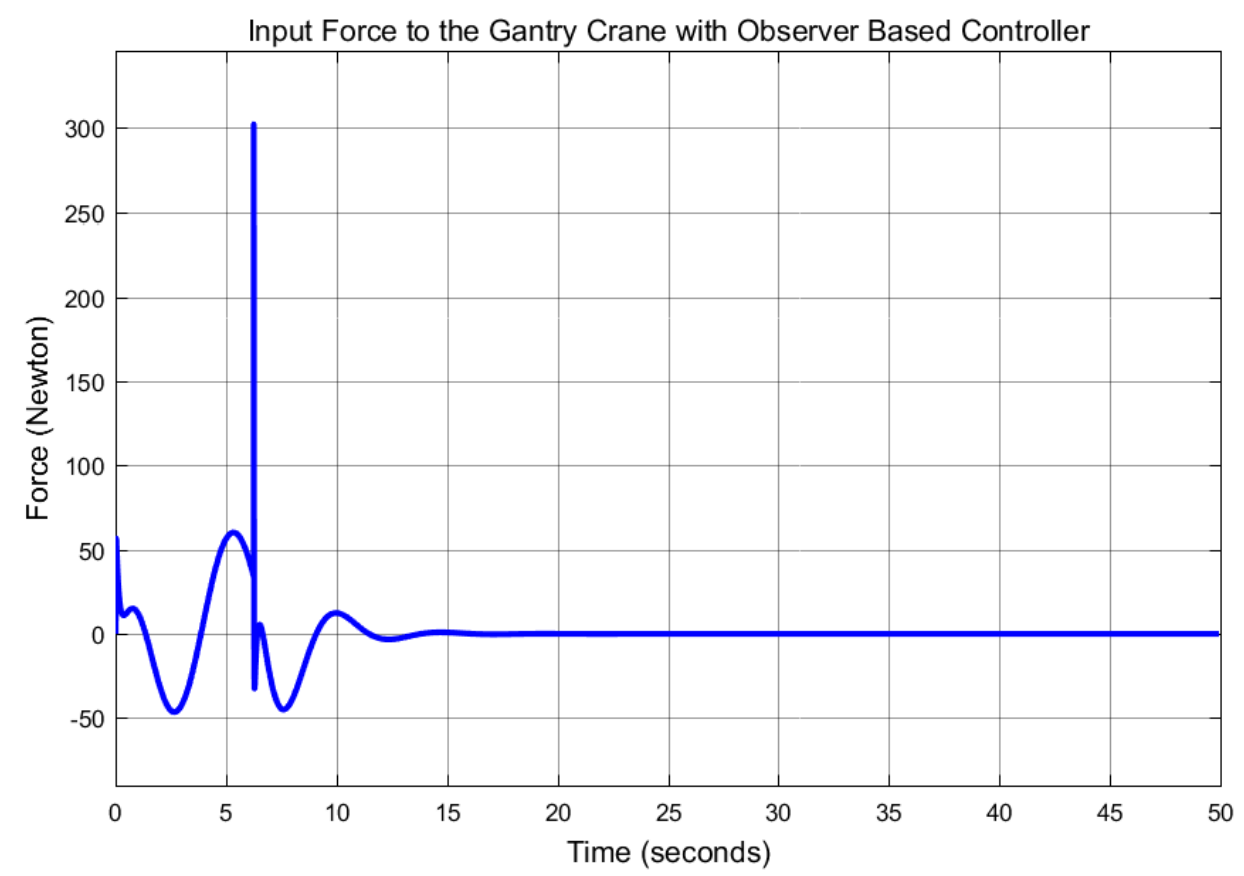

Figure 12 Input Force to the system with observer based controller

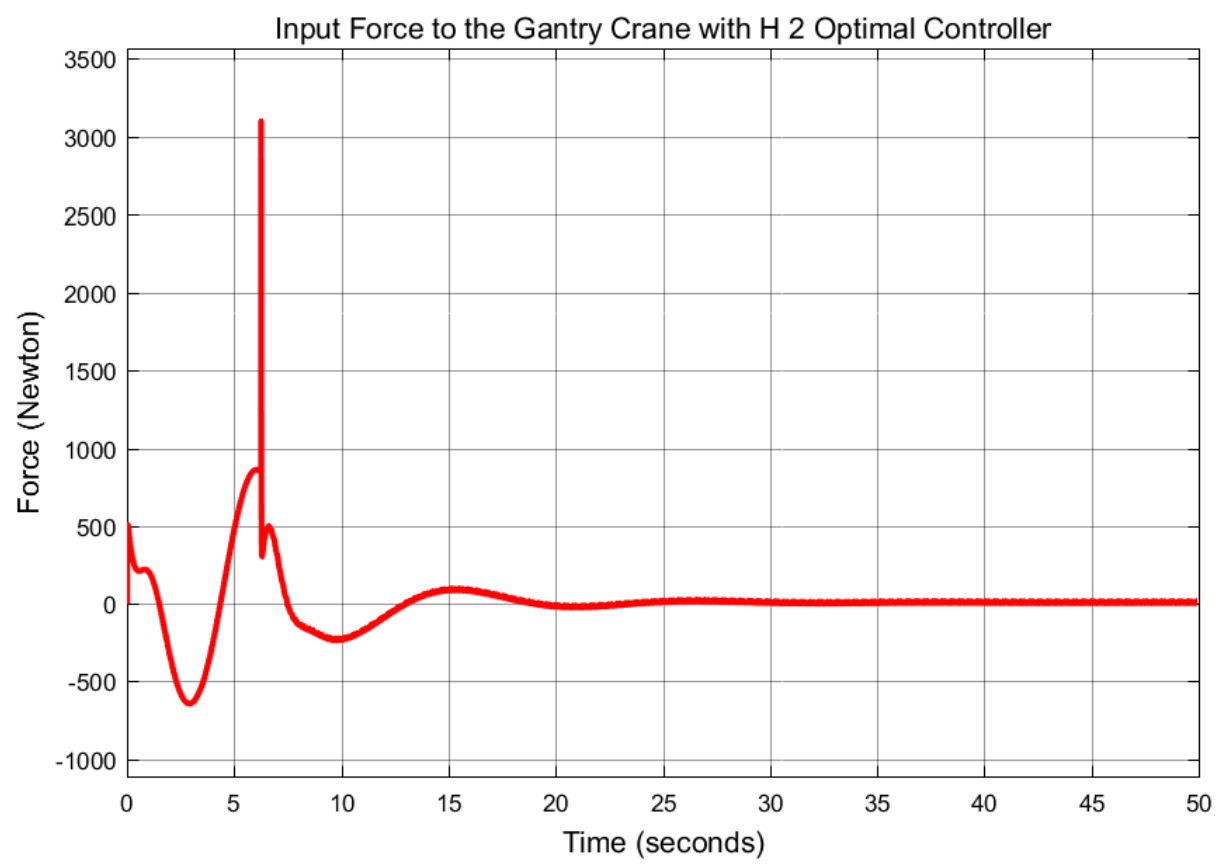

Figure 13 Input Force to the system with H 2 optimal controller

The input force of the gantry crane system with the observer based controller shows improvement in reducing the force amplitude. 
Figure 10 and Figure 11 shows that the gantry crane system with the observer based controller improves the performance of the trolley position and payload angle by minimizing the percentage overshoot and settling time.

\section{Conclusion}

In this paper, a minimum payload angular deflection has been achieved for a gantry crane using a feedback controller. This achievement has been done by controlling the trolley position instead. Comparison of the system with the proposed controllers shows that the system with observer based controller improves the payload deflection and vibration better than the proposed $\mathrm{H} 2$ optimal controller with a minimum force input to the system.

\section{Reference}

[1]. Nguyen H. H et al. "Nonlinear Control of a Gantry Crane System with Limited Payload Angle" International Journal of Electrical and Electronics Engineering, Vol. 5, Issue 8, 2018.

[2]. Ayodeji O. et al. "Vision Based Control of Gantry Crane System" Eskisehir Technical University Journal of Science and Technology A-Applied Sciences and Engineering, Vol. 19, Issue 4, pp. 1023-1032, 2018.

[3]. Sturzer D. et al. "A Closed Loop Stability Analysis of a Gantry Crane with Heavy Chain and Payload" International Journal of Control, 7179: pp. 1-13, 2017.

[4]. Ospina Henao PA. et al. "Dynamic Analysis and Control PID Path of a Model Type Gantry Crane" J Phys Conf Series, 850:12004, 2017.

[5]. Ashwani K. et al. "Automated Control and Optimization of Overhead Cranes" International Journal of Manufacturing, Vol. 7, Issue 3, pp. 41-68, 2017.

[6]. Da-peng Z. et al. "Variational Analysis of Mid Span Deflection of Gantry Cranes" Journal of Central South University, Vol. 24, Issue 1, pp. 2705-2716, 2017.

[7]. Tuan LA. "Design of Sliding Mode Controller for the 2D Motion of an Overhead Crane with Varying Cable Length" Journal of Automotive Control Engineering, Vol. 4, Issue 8, 2016. 